This is the peer reviewed version of the following article: Berge, M. S. (2018) How Do We Understand Partnership Working? Experiences from a Telecare Project. Social Policy \& Administration, 52: 50-66, which has been published in final form at https://doi.org/10.1111/spol.12273. This article may be used for non-commercial purposes in accordance With Wiley Terms and Conditions for self-archiving. 


\section{How do we understand partnership working: Experiences from a telecare project}

Mari S. Berge, University of Stirling, Stirling, UK and Centre for Care Research, Bergen University

College, Bergen, Norway

This is the peer reviewed version of an article accepted for publication in Social Policy \& Administration published by Wiley-Blackwell. Article is available at:

https://doi.org/10.1111/spol.12273. This article may be used for non-commercial purposes in accordance With Wiley Terms and Conditions for self-archiving

\section{Abstract}

Implementing telecare requires experience and knowledge from different disciplines and sectors; business, technology and care. The uptake of telecare has been slow, which is assumed to be caused by difficulties in cooperation within telecare partnerships. This paper presents a new approach to improve understanding of telecare partnerships. The approach builds on theories of trust and partnership working and is informed by rational choice theory.

Within this paper the approach is applied to recent experiences from a telecare project in Norway, to demonstrate how different ways of interpreting the complex social interactions in telecare partnerships yield new insight and understanding. Examples from the Norwegian project illustrate how different understandings of actions and choices affected trust and caused either improved or deteriorated cooperation in the partnership. The partners that were able to develop trust through a common evaluation of the problems, cooperated better. However, when partners lacked or had insufficient knowledge, either of each other or of the situation, this led to disparate understandings that threatened trust and affected further cooperation. The new approach presented here is helpful in analyzing and understanding the actions of different partners within a telecare partnership and 
identifying why things worked well or went wrong. The approach may have wider relevance for other partnerships.

\section{Keywords}

Telecare; Trust; Values; Partnership Working, Rational Choice Theory; Care Technologies Introduction

Telecare is the use of sensor technology at home to enable people to remain safe and keep up their daily life whilst being assured that if an incident happens, the most appropriate response will be activated (Telecare Service Association 2013). Telecare represents a relatively new service in health and social care, and research to date has considered different perspectives on telecare. The focus has been on users (Kubitschke et al. 2010, Bowes and McColgan 2012), carers (Davies et al. 2013), acceptance and barriers to uptake (Sanders et al. 2012, Kerbler 2013), ethical issues (Hofmann 2013), economic issues (Kubitschke et al. 2010, Sorell and Draper 2012), organizational changes, and how telecare influences health and social policy (Chrysanthaki et al. 2013).

Telecare involves multiple and disparate actors assessing, acquiring and implementing technology (Sugarhood et al. 2013) and several transactions thus occur at the crossroads of technology, business and care (Browning et al. 2009, Milligan et al. 2011, Roberts et al. 2012). Difficulties caused by partners having different perspectives in telecare projects are recognized (Chrysanthaki et al. 2013) and have been found to affect cooperation when implementing telecare (Milligan et al. 2011, Sugarhood et al. 2013). This might consequently influence the running of services, affecting safety and quality. There is, however, insufficient evidence to link successful cooperation directly to positive service user outcomes (Rummery 2009). Differences in understandings and values and the lack of mutual communication between partners may hamper the introduction of telecare (Greenhalgh et 
al. 2012). Despite identifying these challenges in telecare partnerships the literature, in general lacks recognition and discussion of the complex social interactions within these partnerships, and how they influence successful cooperation.

This gap in the literature needs to be addressed, since multi-stakeholder partnerships in telecare are likely to increase. Telecare is predicted to play an important role in future health and social service plans in several European countries, USA and Japan (Kubitschke et al. 2010). This paper uses Sloan and Oliver's definition (2013: 1827) of multi-stakeholder partnerships: 'formalized arrangements in which organizations from diverse sectors (private, public and not-for profit) commit to work together in mutually beneficial ways to accomplish goals they could otherwise not achieve alone'. This definition recognizes both potential diversity between the stakeholders and their interdependence in aspiring to achieve mutually beneficial goals. Such goals can include both social and strategic business benefits, for example, improved community care services for municipalities and a new market for telecare companies.

The paper discusses a multi-stakeholder partnership in Norway established to implement telecare in a community care service and then evaluate its impact. The partnership included a telecare company delivering the technology, a municipality implementing telecare in their community care services and an academic institution conducting the evaluation. Despite identifying and working towards a mutual goal, the partnership experienced several challenges as they worked together to achieve this.

The purpose of the paper is to achieve better understanding of the interactions within telecare partnerships. Telecare partnerships involve multiple actors from different 'worlds' working together. The literature on multi-stakeholder partnerships emphasizes the importance of trust for effectiveness. This literature echoes earlier theoretical discussion about interaction that focused on different partners holding different values. The review of this literature offers a new way of looking 
at telecare partnerships. A new approach is developed here, drawing together concepts from the literature: trust, interdependence and rational versus opportunistic behaviour in multi-stakeholder partnerships. This approach is then applied to empirical situations from the Norwegian project to demonstrate how it leads to a more useful understanding of telecare partnerships.

\section{Telecare partnerships - multiple actors from different 'worlds'}

Telecare partnerships involve multiple partners that assess, acquire, implement and evaluate technology in care (Sugarhood et al. 2013), indicating several interactions in the crossroads of technology, business, and care (Browning et al. 2009, Milligan et al. 2011, Roberts et al. 2012). Telecare partnerships are characterised by disparate partners holding and contributing different resourches to transactions that affect all those involved. The concept of transaction refers to sequences of interaction that are systematically governed by reciprocity; where input from one partner releases contribution from the others. Transactions are a key mechanism within partnerships as they require the partners to establish mutual values (Barth 1966). Different partners come from different cultures and contribute different knowledge (Schein 2010). A lack of integration between cultures affects cooperation negatively (Greenhalgh et al. 2012). 'Integration of cultures' may be better understood as an integration of values, as culture consists of basic values that underpin actions. Values represent stable judgments, which a person is unlikely to act against. Actions and choices expose underlying values. By repeatedly resolving dilemmas together, partners may influence each other's values, leading to more consistency of values between partners (Barth 1966, Barth 2007). The partners in telecare need to relate to the different cultures of other partners; the partnership's mutual culture and that of the organization where they belong (Riggs et al. 2013). 
Telecare partnerships are likely to include vendors offering telecare, the service provider customers buying and implementing telecare, which includes care staff; and in the Norwegian project, researchers from an academic institution. The vendors have had considerable influence on the development of telecare due to their thorough knowledge of the technology, which other stakeholders often lack. Consequently the vendors have the opportunity to push technology (Milligan et al. 2011) which may not match the actual need for telecare. Customers, such as the local municipality in Norway, will be more focused on matching the technology with their specific needs. The vendors need to ensure a profitable business that adjusts to changes in the market. The custumers are buying and implementing telecare in care services. They are also responsible for the quality and safety of the service offered to the end-users and for meeting end-users' demands within limited budgets. They need to gain knowledge and experience about innovative alternatives. The researchers are responsible for the research and evaluations and are expected to give an objective account of the implementation. In telecare partnerships therefore, there are multiple partners from different 'worlds' holding disparate knowledge. They may benefit from pursuing individual goals, however cooperating towards a mutual goal may achieve more than they could individually.

\section{Trust in multi-stakeholder partnership}

Given these different 'worlds', it is helpful to have concepts that enable understanding of what happens when people from these worlds work together. Literature highlights that challenges in partnership cooperation are a longstanding issue, especially in multi-stakeholder partnerships and that these remain difficult and poorly understood (Mohr and Spekman 1994, Riggs et al. 2013, Sloan and Oliver 2013). Telecare, as already outlined, requires knowledge from different disciplines and sectors thus, partnership working appears to be necessary for its implementation. Literature suggests that trust, communication, commitment and the ability to take the other's perspective are key to 
partnership success (Mohr and Spekman 1994, Ansell and Gash 2007). Trust is identified as the most important factor in successful relationships (Riggs et al. 2013), especially when there is diversity in values between partners (Mayer et al. 1995), which is the situation in telecare partnerships.

This paper defines trust as the willingness to take risk and rely on another's actions in a situation where there is a risk of opportunism, drawing together ideas from Mayer et al (1995) and Williams (2001). Trust has both rational and affective dimensions. The rational dimension reflects assessment, following repeated interactions, as to whether or not others are trustworthy and to what extent they can be expected to act reliably (Sloan and Oliver 2013). The affective dimension relates to feelings and emotions and reflects genuine care and concern between individuals. The development of affect-based trust is related to frequent interactions, is linked to people rather than roles (Sloan and Oliver 2013), and needs time to develop (Parkhe 1998, Harrison and Furlong 2012, Riggs et al. 2013).

Trust building is a dynamic process, occasionally interrupted by critical emotional incidents that evoke negativity among partners. The resolution of negative situations can, however, result in trust growing, thus turning a negative incident into a positive outcome (Sloan and Oliver 2013). Partners need to have opportunities to work together to solve situations in order to get to know each other (Riggs et al. 2013). Partnerships yield both opportunities and constraints with regard to trust.

Joining a telecare partnership suggests acceptance of interdependence to achieve the desired outcome. Interdependence requires partners to have trust and confidence that other partners will fulfil their obligations (Mohr and Spekman 1994). Everyone is dependent on each other in committing to the mutual goal, and in sharing responsibility for the processes towards it (Sloan and Oliver 2013). In order to commit, partners need to be confident that all partners respect each other's perspectives and interests. Weak interdependence appears to make it difficult to build trust, as possible opportunities outside the partnership can be considered. High interdependence might 
enhance the effort to participate and commit even where trust is weak, and enable conflict situations to be managed collaboratively (Ansell and Gash 2007). Joining a telecare partnership where all partners individually possess essential means to achieving the mutual goal is likely to cause high interdependence. Due to their high interdependence, one partner acting opportunistically would likely cause the relationship to suffer and thus the whole partnership would suffer (Mohr and Spekman 1994). Das and Teng (1998) use cheating as an example of opportunistic behaviour. It seems unlikely that partners will rely on someone who is perceived to cheat in a situation where they need to commit. Their interdependence entails vulnerability that increases risk, and when risk is high, trust is essential (Morgan and Hunt 1994). Trust and interdependence are suggested to be partly endogenous as they are shaped positively and/or negatively by the collaborative process itself (Ansell and Gash 2007).

Das and Teng (1998) refer to opportunism as: 'self-interest seeking with guile' while Soanes and Stevenson (2014) say it is 'taking opportunities as they appear without planning or principle'. The definition of trust includes risking opportunism. Partners may sometimes appear to threaten trust by acting 'opportunistically'. However, rational choice theory would encourage a closer analysis and investigation of the motivations of these partners suggesting that the actions are rational rather than opportunistic. In rational choice theory, all activities that actors use to achieve their goal in transactions are seen by them to be rational. Rational choice theory suggests that actors will always aim to achieve the equal of or more than they lose (Barth 1966, Barth 2007). The resemblance between these concepts depends on how the concept 'opportunism' is perceived. Parkhe (1993) suggests that individual rational actions might be interpreted as opportunistic when they are not yielding the best gain to the partnership, only to the individual. Recognizing an action as being rational instead of opportunistic may be vital to a partnership. 
Whether actions and choices are perceived as being rational or opportunistic will influence how partners assess trustworthiness. Partners base their assessment on the knowledge they bring to and acquire from each transaction. However, insufficient or false information will alter the evaluation and may lead to people feeling cheated, or to behaviour that is understood by others as opportunistic. When partners have mutual understanding of values, they are more likely to understand actions as rational rather than opportunistic, which may lead to greater trust.

Much is at stake, and the partners are unlikely to be willing to risk allying with partners whom they do not trust (Ansell and Gash 2007). Trust is found to be essential and without it, partners will lack confidence in each other and view each other with suspicion, to the detriment of the alliance (Das and Teng 1998). Shared values and high interdependence will encourage trust building.

\section{Understanding telecare partnerships - a new approach}

The literature offers different ways of investigating telecare partnerships to enhance understanding of the interactions taking place within them. This paper develops a new approach to understand telecare partnerships. The approach builds on the concepts of trust, interdependence and rational versus opportunistic behaviour in multi-stakeholder partnerships.

Certain goals in telecare can be achieved only by cooperation between partners from disparate disciplines and sectors, which makes it necessary to establish multi-stakeholder partnerships (Sloan and Oliver 2013). When partners join a multi-stakeholder partnership, the underlying values they bring may conflict with those beneficial to the partnership's mutual goal (Parkhe 1998). The partners are interdependent and this requires them to have trust and confidence in others to fulfil their obligations and achieve the mutual goal (Mohr and Spekman 1994, Mayer et al. 1995). However, in 
telecare partnerships partners may act according to the values of the organization they represent rather than taking actions that benefit the partnership. This may put the collaboration at risk (Barth 1966, Parkhe 1998).

Rational behaviours may be interpreted as opportunistic when the underlying values are not known (Barth 1966, Parkhe 1993). Opportunism challenges trust and causes detriment to the partnership (Das and Teng 1998). For partners to perceive behaviours as rational they need to take the other's perspective and understand their underlying values (Barth 1966, Ansell and Gash 2007). Ideally, partners get to know each other by repeatedly resolving dilemmas together (Riggs et al. 2013). By frequently interacting, they influence and change how each partner evaluates and understands the other's actions (Barth 1966) and improve trust building, which is important for partnerships to succeed (Ansell and Gash 2007).

Application of this approach to aspects of the telecare partnership in Norway helps to illuminate the actions of different partners and the transactions taking place.

\section{Methods}

The empirical data presented here were collected as part of a larger realist evaluation, drawing upon the methodology of Pawson and Tilley (1997), of a telecare project funded by the Norwegian Regional Research Fund. The Norwegian Social Science Data Service provided ethical approval for the project and for the data collection. The empirical data consist of email correspondence between the partners and field notes from observations of 25 meetings with the partners during the first 18 months of the partnership. A considerable number of the interactions took place between meetings 
via email correspondence. Both emails and meetings concerned the establishment and running of the telecare project and the implementation of telecare.

An additional six observations of meetings where the resource group, consisting of dedicated personnel from community care, exchanged experiences, planned and revised the service implementation, are also included. These observations started about six months into the project and lasted for about 12 months. The personnel from the call centre that processed the alarms were not available for observation or interview and their roles and actions emerged from their partners' point of view.

An iterative open coding process was used to analyse the data. Initial reading of the literature highlighted potentially relevant concepts, which guided the first coding of the data. From this process a set of themes emerged that paralleled findings from the literature as well as highlighting new areas of interest. The literature identified the concepts of trust, interdependence and rational versus opportunistic behaviour in multi-stakeholder partnerships that were also reflected in the data. This highlighted the usefulness of the concepts identified from literature in understanding the emerging findings. This paper describes specific events and time periods from the development of the telecare partnership which are used to illustrate how the approach developed here is useful. The paper specifically focuses on situations where partners are required to rely on each other while risking opportunism; situations where rational actions are prone to be perceived as opportunistic, thus challenging trust; and situations where interdependence is weak.

Limitations to the study 
This is a relatively small project, therefore the drawing of conclusions must be limited and the results should be regarded as indications until further refinement and tests of the approach. The author being part of the project may have influenced objectivity in the interpretations and analysis.

\section{Findings}

Experiences from a telecare partnership

First, I seek to recognize the partners' underlying values and explore their reasons for joining in the partnership. Then I identify situations within the partnership where interactions caused actions and choices that the partners perceived as being opportunistic and therefore challenged trust. I outline these situations as they appeared to the partners in physical and electronical interactions. Thereafter I seek to explore the same actions and choices from a rational perspective, exposing underlying values that are rooted in partners' original cultures. I present sequential situations in order to demonstrate how interdependence and trust develop and influence cooperation. The situations discussed are interactions where input from one partner releases contribution from the others, which rational choice theory labels as transactions. Because partners systematically aim to gain from these interactions, their contribution exposes their assessment of the transaction and their underlying values.

Developing the multi-stakeholder telecare partnership

An international telecare company initiated the partnership by inviting an academic institution to establish a research project to evaluate the impact of telecare in local settings. Telecare was not 
widely known in Norway at that time, thus a research project would provide valuable national experience and feed into policy development (Helse- og omsorgsdepartementet 2011a). The company held an established position in the field and had been operating globally within the health care market for decades. The actors from the academic institution accepted the invitation to establish the largest telecare project in the country. Based on local knowledge and previous collaboration, the academic institution identified a suitable municipality to join the partnership. These partners collaborated in planning the three-year project.

The company's input to the transaction would be a total telecare solution, including the sensors; the installation and maintenance; and monitoring solutions for a maximum of 250 dwellings. The company also provided the call centre that responded to the alarms. They provided the telecare equipment free of charge. The input from the municipality would be to implement telecare into their organization. They adopted the project administratively, financially and politically, as they would need extra resources to train staff, inform service users and identify services in which to include telecare. The municipality assumed this would be a worthwhile investment as telecare was set to become part of national policy in the near future. The academic institution would be responsible for planning and managing the project; applying for funding; leading the research element and providing education and information to the municipality when required. The research would evaluate the impact of telecare in the municipality. The partners from the academic institution had expertise and experience in both health care and technology, and held a significant role as facilitators between the municipality and the company.

None of the partners had all the necessary resources at their disposal without joining the multistakeholder partnership. 
All partners were encouraged to attend workshops to develop a funding proposal to cover the costs incurred by the academic institution and the municipality. At this time, the company transferred their responsibility to their national branch, a minor firm with only two employees. They chose not to participate in the workshops, as they were very busy attending to new customers due to a growing national interest in telecare. They were, however, regularly informed and consulted by phone and email. This left the bulk of the responsibility for the further planning and decision-making with the academic institution and the municipality.

The first mutual challenge

When the actual work started, the academic and municipality partners were surprised to discover that the company relied on sub-contracted technicians for configuration and installation. These subcontractors were familiar with social alarms but had neither experience nor knowledge of the more advanced telecare technology being used in this project.

The three partners, plus the technicians and the community care staff met regularly to clarify tasks and responsibilities, and to plan the implementation. The community care staff undertook the educational programs concerning telecare offered by the academic institution, assessed the users' need for telecare, and provided them with information about the new service. The academic institution provided findings from relevant international research to the municipality to help underpin their decisions and actions.

The test installation 
The partners agreed on one installation to test the interactions and technology within the existing infrastructure. All partners cooperated in the planning and agreed upon their areas of responsibility. The installation was scheduled and everyone was prepared; the user receiving the telecare; the relatives; the community care staff; the call centre; and the technicians.

On the morning of installation, the company called it off, due to technical incompatibilities, which meant the equipment was not ready for installation. The incompatibilities were unknown to the company, as the technology was new to Norway. The municipality and the academic institution cooperated to minimize the impact of the cancellation while the company attended to the equipment.

The re-scheduled test installation exposed some technical weaknesses that required improvement prior to full scale installation. The company replaced the technicians with one who held better knowledge of the telecare equipment. These incidents delayed the implementation for almost six months.

\section{Emerging challenges}

Following the test installation, the telecare installations continued at a slow pace and when the alerts began, challenges emerged. The operators at the call centre were expected to know how to respond to the alerts, which involved understanding which sensor was activated, which response was required, and how to act upon this knowledge. The operators were experienced in social alarms but had never operated telecare alarms, and were unable to interpret the information from the telecare sensors. Therefore, they contacted the community care staff for every alert, without checking which 
response was required. The community care staff grew increasingly frustrated over the number of inaccurate calls, to which they could not respond adequately due to lack of information. The community care staff expressed deep concerns. Being unable to assess the situation, they were obliged to visit the service users in response to every alarm, resulting in many unnecessary visits and other tasks put on hold. The users live over a large area and a 40-minute journey was often required just to reach the user. In addition, the technician had to reconfigure and fine-tune devices due to technical incompatibilities resulting in more visits to the users, which required the staff to accompany him and thus to again reschedule other plans. Telecare started to cause a lot of extra time for the community care staff.

These issues arose partly due to lack of knowledge and information and partly due to technical configurations and threatened the running of the municipal services with regard to safety and quality. They also resulted in increased workload for the company in an already strained situation.

The company opts out

When the project had been running for about a year, the company announced their decision to withdraw from the current partnership and stated that they wanted to renegotiate the contract following significant internal changes at the company. They wanted to reduce the number of installations as they claimed no longer to possess the financial means to participate in such a big project. In addition, the national branch of the company and the call centre had been sold, therefore they questioned their further obligations in the project. According to the company, the municipality had not fulfilled their part of the contract, as they had not reached the final goal of 250 installations. 
They also questioned the higher than expected installation costs that had resulted from the need for fine-tuning of the equipment.

The other partners were surprised by the withdrawal of the company and the reasons given by then did not appear to match with the company's previous level of responsibility and actions within the partnership.

\section{Discussion}

The above examples demonstrate how trust is repeatedly challenged in transactions within the partnership as partners interpret situations from the observed choices and actions of others, without always recognizing the underlying values. I will now illustrate how the approach developed in the first part of the paper can be utilized to better understand these situations by revealing the rationale behind the observed actions.

Illuminating underlying values

It is reasonable to assume that the company's underlying values when initiating the project concerned their future sustainability and earning power as these directly affected their continued existence and profitability. They self-evaluated their contribution in the transaction to be beneficial as they planned to gain publicity, trustworthiness from association with the other partners, and access to a new market. The value for the academic institution was an opportunity to expand their research portfolio that is fundamental for publications, funding, teaching and impact in the scientific society (Kunnskapsdepartementet 2005). The municipality's underlying values relate to the 
legislation that holds them responsible for delivering safe services to their inhabitants. They are responsible for organizing and delivering appropriate services to support people to live independent and meaningful lives in relation to others within a given budget (Helse- og omsorgsdepartementet 2011b). Improving services within limited budget is a constraint that requires innovative solutions such as telecare (Helse- og omsorgsdepartementet 2011a). All partners expected to gain from the partnership, all brought in assets that were essential in achieving the mutual aim and all acted according to their values.

Partnership success is suggested to depend on the ability to take a partner's perspective (Mohr and Spekman 1994, Ansell and Gash 2007), and is recognized to be lacking in telecare (Chrysanthaki et al. 2013). Understanding how values affect a partner's behaviour offers a possibility to take that partner's perspective. Understanding which underlying values partners' actions are based on might facilitate working in partnership. However, values can develop and shift when partners work together as they may take partners' perspectives and empathize with their values. They may then start to develop new values and share them in new ways, hence creating steps towards a common culture that facilitates interaction (Barth 1966).

Illuminating interdependence, gains and losses

The partners held complementary assets in the telecare project comprising the research arena, the technology market, human resources, knowledge and experience. The telecare partnership was expected to yield mutual gains for all involved, and the partners were dependent on each other's assets to achieve the common goal (Sloan and Oliver 2013). Telecare was a new field for most partners, thus risk and interdependence with the partners were high (Morgan and Hunt 1994, Riggs et al. 2013). Partners needed to trust that others would fulfil their obligations from the very 
beginning of the partnership (Mohr and Spekman 1994). The mutual goal, to demonstrate the impact of telecare through technical and organizational implementation in the municipality, involved several transactions within the partnership.

Promotion in the market and research evoke different expectations: research usually implies reliability and validity (Morse et al. 2002) whilst promotion and marketing are concerned with demonstrating advantages. Information based on research should have greater impact for policy makers and potential buyers, due to its perceived trustworthiness. Therefore, the company expected that being a partner in the telecare research project would yield positive outcomes. They would benefit from new groups and organizations accepting telecare. This in turn depended on the municipality and the academic institution fulfilling their responsibilities.

The implementation affected many stakeholders in the municipality and organizational changes were required to adjust home care services to fit telecare delivery (Bowes and McColgan 2006, Chrysanthaki et al. 2013). It was found to be beneficial for the municipality to access the academic institution, which provided information and education necessary for preparing them to deliver telecare. The technical resources provided by the company were attractive assets to the municipality as they gave the opportunity to facilitate governmental requirements within budget. The municipality was dependent on the company to supply them with the equipment and the academic institution to provide them with knowledge.

The academic institution should benefit from the implementation of telecare and the evaluation of the project as it should strengthen their expertise and profile in an innovative field that has government backing. The academic institution was dependent on the company and the municipality to carry out the intervention as this would provide the research arena. 
None of the partners expressed doubts when they joined the partnership (Mohr and Spekman 1994) which may be because they all considered their contribution to the transaction as beneficial and each expected to gain more than they would lose (Barth 1966).

Rationality in the first mutual challenge

The national branch of the company had limited resources, and because they had problems fulfilling obligations made by their superiors, they hired sub-contractors to accomplish these. Unfortunately, the sub-contractors lacked the required competencies. This seriously affected the company's transaction as it increased their input, resulting in lower gains. An alternative approach might have been for the company to withdraw at this early stage. Reflecting on the company's basic values and priorities suggests that they were acting rationally by prioritizing paying customers by hiring subcontractors. The sub-contractors lacked knowledge but the company did not spend resources educating them, which could be understood as rational as it provided a cost saving (Barth 1966). The company did not withdraw at this point thus participation still appeared beneficial to them. The municipality and the academic institution appeared unaware of the company's underlying values and thus assumed the company had reduced their input by using sub-contractors. They interpreted the actions of the company as opportunistic, which challenged trust within the partnership (Parkhe 1993).

Rationality in the test installation

The company appeared to prioritize activities yielding income by focusing on other paying customers instead of spending limited resources preparing for the test installation. In being unprepared the 
likelihood of the test installation failing was high and might have risked trustworthiness with the market. The company's rationale in calling off the test installation may have been that they preferred to risk losing trustworthiness with the partnership rather than with the market. The company's gain in the project was tied to achieving trustworthiness in the market, thus this action may be understood as rational to them (Barth 1966). To the academic institution and the municipality it seemed another act of opportunism which added to their impression of the company being untrustworthy (Das and Teng 1998, Parkhe 1993). Their interdependency with the company required them to continue to rely on the company fulfilling their contribution to the transaction. However, these incidents caused an increased risk to effective partnership working (Ansell and Gash 2007, Riggs et al. 2013).

The cancelling of the test installation led to the municipality and the academic institution collaborating to minimise harm, and created an opportunity to develop mutual values and trust: thus the negative situation yielded positive outcomes for them (Barth 1966, Riggs et al. 2013). The company missed this opportunity and they may have felt excluded. Partners from the municipality and the academic institution already had shared experiences from working within the same legislation in community care and their common understanding further facilitated development of mutual values (Barth 1966) and trust (Sloan and Oliver 2013). Empathizing with the company and their challenges appeared more difficult than empathizing with each other. The municipality and the academic institution therefore experienced improved development of shared culture and trust and cooperated in beneficial ways for both, while for the company the situation within the partnership deteriorated (Barth 1966, Riggs et al. 2013). 
Using telecare equipment correctly requires a wide range of knowledge. In the telecare project, every part of the interaction was vital; assessment to fit the right telecare equipment by specially educated community care staff; configuration and installation to activate the right responses by the technician; and receiving and handling alerts by the call centre operators to enable the right response to the specific user. Communication between the three groups was vital, as their areas of responsibility were interdependent and complementary.

The technician and the community care staff cooperated within a shared context when they visited the service users to install telecare equipment and resolve any difficult situation that arose. These shared situations repeatedly exposed their underlying values through choices and actions. Experiencing each other being reliable and trustworthy appeared to develop trust as they cooperated smoothly (Riggs et al. 2013, Barth 1966).

The call centre operators were in a different situation as they were neither familiar with the telecare equipment nor held the necessary knowledge to respond to it. They were remotely situated and their only interactions happened during their response to alarms. In these situations they were unable to respond properly and did not work to resolve challenges together with the other partners. They did not have the same opportunities to build trust and mutual understanding (Sloan and Oliver 2013). Their underlying values remained unknown and they were unable to develop or share culture with the other partners (Barth 1966, Riggs et al. 2013). The interactions between the community care staff, the technician and the call centre meant that two of these had the conditions necessary for building a common culture, trust and cooperation through transactions, while the third did not. 
At the time of the withdrawal, the company appeared to have lost more than they had gained, especially since they had provided the technology without charge. They justified their withdrawal by stating that structural changes in the company's main office had forced them to go back on their obligations. The company also stated that part of their withdrawal was because other partners had not fulfilled their obligations. This might be understood as the company trying to maintain some trustworthiness within the partnership. It does however, indicate that the company evaluated the outcome in the transactions differently.

The context is always changing, thus the company re-evaluated the situation according to their gains and losses within the new context. They had lost more than anticipated due to the problems with lack of resources, the incompatible technology and the call centre. When the project is finished the municipality is required to go to tender for telecare. The municipality's increased knowledge from this project will influence their choice of a new supplier. The company is at risk of exclusion at that point. Municipalities often go for the best offer financially, which might not provide the best technological solutions. Another risk is that a competitor offers both cheaper and better technological solutions. However, the local market is relatively small and the company might evaluate the damage made by their withdrawal to be less than the risk of continued loss of resources in a market that may not pay off. Their interdependence with the partners seems low, thus they may gain more by pursuing new partnerships (Riggs et al. 2013).

The municipality and the academic institution had several opportunities to cooperate and resolve dilemmas, while the company did not (Riggs et al. 2013). Neither did the company share the common knowledge and prior background of the other partners, thus, they lacked opportunities to exchange underlying values and develop mutual culture and trust (Barth 1966). The company's actions and choices appeared opportunistic to its partners; however, by using the approach outlined in this paper 
they appear rational, thus more understandable (Barth 1966). The partners' surprise at the withdrawal of the company indicate their lack of awareness of the company's underlying values.

\section{Conclusion}

Literature demonstrates that telecare partnerships are challenging and that a majority fail, which is suggested to result in slow uptake of telecare. Existing literature does not explore and disentangle how the complex social interactions within telecare partnerships work. This paper aims to address that gap by applying an approach that seeks to understand the interactions between partners in telecare partnerships. The approach builds on theories of trust and partnerships and is informed by rational choice theory.

By looking into what characterizes telecare partnerships certain features emerge that call for attention. Telecare partnerships depend on different partners bringing together disparate knowledge and experience to achieve mutual goals. Partners are interdependent, as each holds different elements of what is necessary to achieve the mutual goal, which they cannot obtain alone. They need to trust each other to act in favour of the partnership. People and organizations from different 'worlds' bring significant qualifications that are appreciated by their partners. However, less attention is given to the fact that different cultures and values are also part of what partners bring. These values are stable judgments that direct actions. Actions and choices will in turn expose underlying values. When partners recognize the values that are guiding the actions, they are prone to understand them as being rational. However, when values are unrecognized, and actions do not appear to enhance the partnership, partners tend to understand them as being opportunistic. Rational actions and choices do not challenge trust, but perceived opportunistic behaviours do. Trust is vital for cooperation and influences how the partnership develops. 
Applying this approach to data from a telecare partnership illustrates how partners that cooperated actively in mutually resolving problems also developed a mutual understanding of what the problems were. Further, they exchanged knowledge about each other's values and criteria for action. These processes enabled them to understand each other's actions and choices as rational instead of opportunistic, and thus avoided challenges to trust. The situations presented here entailed high risk and consequently required high trust. The data illustrate how partners in risky situations tend to perceive actions and choices as being opportunistic instead of rational when trust is low.

The paper draws our attention to some implications for other telecare partnerships. Firstly, known drawbacks in partnership working like loss of autonomy, increased dependence and constraints are frequently ignored in the process of building new partnerships. Secondly, the need to refrain from individual pursuit of goals in favour of mutual ones is challenging when establishing partnerships. Thirdly, it is necessary to be aware of partners' strategic directions, and divergent directions are easier to address when there is trust. Raising awareness of these aspects among potential partners might reduce their possible impact.

The approach developed in this paper improves understanding of the complex social interactions within a telecare partnership by illuminating how different cultures bring disparate values that guide partners' actions and choices. Whether these are understood as being rational or opportunistic, depends on the partners' ability to recognize underlying values and will in turn significantly influence how the telecare partnership develops. 


\section{Acknowledgements}

I am indebted to the Regional Research Centre for Western Norway who funded this telecare project and the Norwegian Nurses Organization for their financial support. I wish to thank Alison Bowes, Louise McCabe, Frode F. Jacobsen and Knut $\varnothing$ vsthus and the anonymous reviewers for their valuable comments and suggestions for improvement. The views expressed in this paper are the author's own. 


\section{References:}

Ansell, C. \& Gash, A. (2007), Collaborative governance in theory and practice. Journal of public administration research and theory, 18, 4: 543-571.

Barth, F. (1966) Models of social organization, Royal Anthropological Institute., London.

Barth, F. (2007), Overview: Sixty years in anthropology. Annual Review of Anthropology, 36: 1-16.

Bowes, A. \& McColgan, G. (2012), Telecare for Older People: Promoting Independence, Participation, and Identity. Research on Aging, 35, 1: 32-49.

Bowes, A. M. \& McColgan, G. M. (2006), Smart Technology and Community Care for Older People: Innovation in West Lothian. Scotland Edinburgh: Age Concern Scotland.

Browning, S. V., Tullai-McGuinness, S., Madigan, E. \& Struk, C. (2009), Telehealth: is your staff ready to implement? A descriptive exploratory study of readiness for this technology in home health care. Home Healthcare Nurse, 27, 4: 242-248.

Chrysanthaki, T., Hendy, J. \& Barlow, J. (2013), Stimulating whole system redesign: Lessons from an organizational analysis of the Whole System Demonstrator programme. Journal of Health Services Research \& Policy, 18, 1 suppl: 47-55.

Das, T. K. \& Teng, B.-S. (1998), Between trust and control: developing confidence in partner cooperation in alliances. Academy of management review, 23, 3: 491-512.

Davies, A., Rixon, L. \& Newman, S. (2013), Systematic review of the effects of telecare provided for a person with social care needs on outcomes for their informal carers. Health \& social care in the community, 21, 6: 582-597.

Greenhalgh, T., Procter, R., Wherton, J., Sugarhood, P. \& Shaw, S. (2012), The organising vision for telehealth and telecare: discourse analysis. BMJ open, $2,4$.

Harrison, J. \& Furlong, G. T. (2012), Building Trust in Business Partnerships. (ed)^(eds), Agree Dispute Resolution, IRC eNews, Queens University.

Helse- og omsorgsdepartementet (2011a), Innovasjon i omsorg. (ed)^(eds), Norges offentlige utredninger, Oslo, Departementenes servicesenter, Informasjonsforvaltning. p. $181 \mathrm{~s}$.

Helse- og omsorgsdepartementet (2011b), Lov om kommunale helse- og omsorgstjenester m.m. . (ed)^(eds), Oslo, Helse- og omsorgsdepartementet,.

Hofmann, B. (2013), Ethical challenges with welfare technology: a review of the literature. Science and engineering ethics, 19, 2: 389-406.

Kerbler, B. (2013), The elderly and a remote home care: The case of Slovenia. Stanovnistvo, 51, 1: 2341.

Kubitschke, L., Cullen, K. \& Múller, S. (2010), ICT and Ageing: European Study on Users, Markets and Technologies, Final Report. Brussels: Commission of the European Communities.

Kunnskapsdepartementet (2005), Lov om universiteter og høyskoler (ed)^(eds), Oslo, Kunnskapsdepartementet.

Mayer, R. C., Davis, J. H. \& Schoorman, F. D. (1995), An integrative model of organizational trust. Academy of management review, 20, 3: 709-734.

Milligan, C., Roberts, C. \& Mort, M. (2011), Telecare and older people: Who cares where? Social science \& medicine, 72, 3: 347-354.

Mohr, J. \& Spekman, R. (1994), Characteristics of partnership success: partnership attributes, communication behavior, and conflict resolution techniques. Strategic management journal, 15, 2: 135-152.

Morgan, R. M. \& Hunt, S. D. (1994), The commitment-trust theory of relationship marketing. the journal of marketing, 58, July: 20-38.

Morse, J. M., Barrett, M., Mayan, M., Olson, K. \& Spiers, J. (2002), Verification strategies for establishing reliability and validity in qualitative research. International Journal of Qualitative Methods, 1, 2: 13-22.

Parkhe, A. (1993), Strategic alliance structuring: A game theoretic and transaction cost examination of interfirm cooperation. Academy of management journal, 36, 4: 794-829.

Parkhe, A. (1998), Building trust in international alliances. Journal of World Business, 33, 4: 417-437. 
Pawson, R. \& Tilley, N. (1997) Realistic evaluation, Sage, London.

Riggs, E., Block, K., Warr, D. \& Gibbs, L. (2013), Working better together: new approaches for understanding the value and challenges of organizational partnerships. Health promotion international: dat022.

Roberts, C., Mort, M. \& Milligan, C. (2012), Calling for Care:'Disembodied'work, teleoperators and older people living at home. Sociology, 46, 3: 490-506.

Rummery, K. (2009), Healthy partnerships, healthy citizens? An international review of partnerships in health and social care and patient/user outcomes. Social science \& medicine, 69, 12: 17971804.

Sanders, C., Rogers, A., Bowen, R., Bower, P., Hirani, S., Cartwright, M., Fitzpatrick, R., Knapp, M., Barlow, J. \& Hendy, J. (2012), Exploring barriers to participation and adoption of telehealth and telecare within the Whole System Demonstrator trial: a qualitative study. BMC health services research, 12, 1: 220.

Schein, E. H. (2010) Jossey-Bass Business and Management : Organizational Culture and Leadership Jossey-Bass, Hoboken, NJ, USA.

Sloan, P. \& Oliver, D. (2013), Building Trust in Multi-stakeholder Partnerships: Critical Emotional Incidents and Practices of Engagement. Organization Studies: 0170840613495018.

Soanes, C. \& Stevenson, A. (2014), Ordnett.no. In: C. Soanes \& A. Stevenson (ed)^(eds), Oxford Dictionary of English, Oslo, Kunnskapsforlaget.

Sorell, T. \& Draper, H. (2012), Telecare, Surveillance, and the Welfare State. American Journal of Bioethics, 12, 9: 36-44.

Sugarhood, P., Wherton, J., Procter, R., Hinder, S. \& Greenhalgh, T. (2013), Technology as system innovation: a key informant interview study of the application of the diffusion of innovation model to telecare. Disability and Rehabilitation: Assistive Technology, 9, 1: 79-87.

Telecare Service Association (2013), What is telecare? (ed)^(eds).

Williams, M. (2001), In whom we trust: Group membership as an affective context for trust development. Academy of management review, 26, 3: 377-396. 